\title{
The Biodiversity Paradigm: Building Resilience for Human and Environmental Health
}

\author{
Ruchi Shroff ${ }^{1} \cdot$ Carla Ramos Cortés $^{1}$ \\ Published online: 11 November 2020 \\ (c) Society for International Development 2020
}

\begin{abstract}
It is a well-established fact that biodiversity is pivotal to human and planetary health, completely entwining biodiverse natural systems into a continuum, through our food systems, into human health. This means there is an intimate connection between the biodiversity of the soil, the biodiversity and interrelationships of cultivated and wild plants and animals. This article looks through an ecological sciences perspective at the interconnections and interrelations between human health and Earth's health. But regardless of the wide recognition of the benefits of biodiversity, we are seeing a political and economic landscape which actively runs contrary to and further erodes diversity in favor of the globalized industrial food system, seed uniformity and further centralization through false tech solutions. A food system which is responsible for both setting the preconditions for the severity of the global COVID-19 pandemic by weakening human and animal health through an explosion of non-communicable diseases. The way forward is instead shown by small farmers, local communities and gardeners who are already implementing biodiversity-based organic agroecology, which both preserves and rejuvenates the health continuum between the soil, plants, animals, food and humans. Acting as a holistic paradigm shift where diversity in all areas is cultivated for ecological resilience.
\end{abstract}

Keywords Biodiversity $\cdot$ Health $\cdot$ Food systems transformations $\cdot$ Industrial agriculture $\cdot$ Agroecology

It is now a well-established fact that biodiversity is pivotal to both human and planetary health, completely entwining biodiverse natural systems into a continuum, through our food systems, into human health. This means there is an intimate connection between the biodiversity of greater ecosystems, soil—founded on microbial biodiversity-and the biodiversity and interrelationships of cultivated and wild plants and animals, which has given rise to diverse cultures and knowledge systems, including seed and crop diversity, and diets. In no moment has the importance of these interconnections become more apparent than during the COVID-19 pandemic, which has exposed the extant and interconnected precarities of our global systems. It has shown how the health emergency we are facing globally is deeply connected to the health emergency the Earth is facing in terms of steady environmental degradation, the extinction and disappearance of species and the climate emergency.

Ruchi Shroff

ruchi@navdanya.net

1 Navdanya International, Rome, Italy
These are all factors which have been largely caused by our current globalized, industrial agricultural system, as its entire model runs contrary to the cultivation of diversity for human and ecological health. This system provides nutritionally dead and toxic food, creating the modern explosion of noncommunicable diseases. It has been proven to degrade ecosystems through pollution, high fossil fuel use, soil deterioration, and deforestation. Sitting at the root of these issues is the unprecedented erosion of biodiversity.

Despite wide-spread international calls to curve the sixth mass extinction, no single goal of the Convention of Biological Diversity's Aichi Biodiversity Targets, for the second consecutive decade, have been met. ${ }^{1}$ In some cases, biodiversity loss has been made worse as no action has been taken to curb pesticide use, pollution, fossil fuels and plastics. ${ }^{2}$

\footnotetext{
1 https://www.theguardian.com/environment/2020/sep/15/every -global-target-to-stem-destruction-of-nature-by-2020-missed-unreport-aoe Accessed September 2020. https://www.cbd.int/gbo5 Accessed September 2020.

2 https://www.theguardian.com/environment/2020/sep/15/every -global-target-to-stem-destruction-of-nature-by-2020-missed-unreport-aoe Accessed September 2020.

https://www.cbd.int/gbo5 Accessed September 2020.
} 
This comes when such international fora are calling for an increase in biodiversity in nutrition, linking biodiverse diets as the vectors of health-now a widely accepted fact. Biodiversity is, hence, needed at every level of the food system. But despite this international recognition, ${ }^{3}$ the key threat remains the active promotion of a food system which runs contrary to its preservation. These threats come in the form of greater promotion and expansion of the industrial agricultural model, including the use of biodiversity-harming agrochemicals, a monocultural push toward seed uniformity and further centralization of genetic resources. All having devastating consequences in the form of creating nutritional precarity on all ends of the food system-whether through degraded health as consequence of industrial diets, or through loss of local access to biodiverse foods.

Demonstrating this, is the paradoxical example of farmers,labourers, and migrant workers in India ${ }^{4}$ who were left without income to starve in the wake of the Coronavirus shutdowns while food piled up to waste. With nowhere to sell and no way to transport the winter commodity crops, farmers had no choice but to leave their harvests to rot in the fields. ${ }^{5}$ Ironically, this exposed a deep precariousness in the industrial agricultural system, as these farmers-despite being farmers-faced a greater risk of starvation than of contracting COVID. This was especially the case for cashcrop industrial farmers who grew only commodity monocultures and non-food crops like cotton, coffee, or wheat for exportation. Such collapses went on to create worldwide food supply chain disruptions and shortages which disproportionately affected the poorest sectors. ${ }^{6}$ In contrast, farmers and communities who based their local food system on biodiversity, were in fact more nutritionally resilient and self-sufficient during the lockdowns. In Mexico City, this

\footnotetext{
3 https://www.fao.org/state-of-biodiversity-for-food-agriculture/en/ Accessed June 2020.

${ }^{4}$ In India who went through the worst migrant crisis: https://www. thehindu.com/data/data-80-of-urban-workers-lost-jobs-during-coron avirus-lockdown-survey/article31569572.ece Accessed September 2020.

5 https://www.reuters.com/article/us-health-coronavirus-food-suppl ies-insi/coronavirus-upends-global-food-supply-chains-in-lates t-economic-shock-idUSKBN21L2V7 Accessed May 2020.

https://www.nytimes.com/2020/04/11/business/coronavirus-destr oying-food.html Accessed May 2020.

https://www.theguardian.com/world/2020/apr/09/us-coronaviru s-outbreak-agriculture-food-supply-waste Accessed May 2020.

https://www.ipes-food.org/_img/upload/files/COVID-19_Commu niqueEN(2).pd Accessed May 2020.

${ }^{6}$ https://www.ipes-food.org/_img/upload/files/COVID-19_Commu niqueEN(2).pd Accessed May 2020

7 Chinampas are floating islands constructed by the Aztecs in the southern areas of Mexico City on Lake Texcoco. They were traditionally used for food cultivation and although, in modern-day they are mostly used as tourist attractions.
}

included a resurgence of chinampa ${ }^{7}$ farming in order to feed the populations of Mexico City as globalized supply chains collapsed. ${ }^{8}$ In Italy ${ }^{9}$ and the United States ${ }^{10}$ there was a surge of community supported and local farm sales to supplement empty grocery stores. In India, this was also the case in the Sundarbans islands in West Bengal, ${ }^{11}$ where villagers were used to cultivating their own diverse foods. As one woman said, '...Though the coronavirus has created a temporary deadlock, we know that we will survive. Our fields are full of potatoes, onions, bitter gourds, snake gourds and drumsticks. There is no dearth of paddy either. Our ponds are full of fish. So, there is no question of us dying of starvation.. ${ }^{12}$

Through such examples we can start to see the paving of a way forward, as small food producers, gardeners and local communities are already implementing biodiversity-based organic agroecology, which both preserves and rejuvenates the health continuum between the soil, plants, animals, food and humans. This acts as a holistic paradigm shift where diversity embodies a deeper significance of not just a nutritional or economic resource for general health, but strengthened intimate relations between local communities and the land.

\section{The Biodiversity Web}

Interrelations between multiple plant and animal species, alongside natural processes, work to co-create our natural world. They provide clean air and water, rejuvenate soil fertility, create niches for multiple species, as well as provide a wide variety of foods and genetic resources-functions which render healthy ecosystems resilient to sudden climate changes, natural disasters, or disease outbreaks. All of these processes have a direct and tangible tie to human health, as an intimate connection exists between the biodiversity of the soil, microorganisms, plants and their seed, wild as well as crop varieties and species, animals, and the biodiversity of our diets and gut. In other words, health is a continuum

\footnotetext{
8 https://www.atlasobscura.com/articles/mexico-city-chinampascoronavirus Accessed June 2020.

9 https://comune-info.net/quarantena-senza-supermercato/ Accessed March 2020.

${ }^{10}$ https://www.npr.org/2020/05/10/852512047/as-food-supply-chain -breaks-down-farm-to-door-csas-take-off Accessed May 2020.

https://www.capitalpress.com/ag_sectors/smallfarm/record-numbe rs-of-csa-customers-still-buying-direct-from-farms-this-fall/artic le_21354294-027f-11eb-9215-339b618fb46e.html Accessed September2020

11 https://ruralindiaonline.org/articles/sundarbans-mousani-eats-bette r-in-lockdown/ Accessed 2 October 2020.

12 Original quote from https://ruralindiaonline.org/articles/sunda rbans-mousani-eats-better-in-lockdown/ Accessed 2 October 2020.
} 
from the earth to our bodies, dictated by the interconnection and the interrelatedness between humans, nature's biodiversity, and its systems. Traditionally, agricultural systems and their diets have co-evolved over millennia in local ecological contexts, forming specific situated knowledges and deep relationships of stewardship between farmers and the land. This is the interconnected web of biodiversity, where each factor goes on to equally constitute the other.

\section{Soil, Food and the Microbiome}

The interrelation between human health and nutrition is determined by the connecting pathways between soil health, plant health, animal health, and therefore human health. Plant nutrient compositions, that are consumed by animals and humans, are determined by the nutrient and microbial composition of the soil in which they grow. The health of animals and plants then determines the health of an overall ecosystem. Unmindful of these connections, industrial agricultural practices have altered the chemical and microbial composition of the soils and quality and availability of water, having direct influence on ecosystemic health and nutrient availability.

Healthy soils are made up of several interrelated factors, such as organic matter, moisture, mineral content and communities of thousands of organisms and microorganisms. Soil may in fact be the most diverse ecosystem on the planet, with one gram of soil containing up to one billion bacteria cells and fungi mycelium, and countless other insects, arthropods and nematodes (Wagg et al. 2014). The health of the biodiversity of the soil is directly linked to above ground diversity (Wardle et al. 2004; Wagg et al. 2014). The connections between these organisms and many other natural processes work to fix essential nutrients into soils, which in turn become available for plant absorption.

The crux of thisinterlinkage can be seen through the soil's microbiome, or the collection of diverse microorganisms which create symbiotic relationships with plants (Wardle et al. 2004; Blum et al. 2019; Hirt 2020). These symbiotic relationships can be most evidently seen in the plants' rhizosphere, or the area of soil in direct contact with plants' roots. ${ }^{13}$ The plant's microbiome then serves to fix essential nutrients like nitrogen, regulate against environmental stressors, enhance immune function, provide protection against pathogens through crowding out areas where

\footnotetext{
13 Around the plant's roots are tiny hairs which create niches for these microorganisms constituting a large part of the plant's microbiome.

14 Plant metabolites make up the plant's secondary metabolism, and are responsible for the production of a variety of chemical compounds that are necessary for the plant's growth, survival and reproduction. In this specific instance, the microbiome of the plant aids
}

pathogenic microorganisms could take over, and the creation of plant metabolites ${ }^{14}$ (Blum et al. 2019; Hirt 2020).

So, in this sense, healthy soils allow for the correct and essential amounts of micronutrients, vitamins, minerals, metabolites, proteins and carbohydrates to be found in edible plants. The soil microbiome has a direct effect on the human microbiome's composition and diversity through both close contact with the soil itself and through diet. Being a symbiotic relationship, much like the plant's microbiome, our microbiome holds the key roles of regulating our metabolism, providing pathogen resistance and enhancing immune functions, regulating hormones and the circadian rhythm, and contributing to nutrient generation and absorption (Salonen et al. 2012). A healthy diversity of taxa in our microbiome has been directly correlated with improved immune function, reduction of inflammatory diseases, and better overall health (von Hertzen et al. 2011). Since the soil acts as a reservoir of diverse microbiota, the two can be seen as forming a sort of 'super-organism' as both work to constitute the other (Blum et al. 2019; Hirt 2020). This means any depletion in the diversity of the soil microbiome has a direct effect on the diversity of the human gut, resulting in negative health effects.

Hence, a diverse diet, along with contact with a diverse ecosystem, then directly promotes a diversity of healthy gut microbiota (Ruggles et al. 2018; Blum et al. 2019). Although, with the transition to industrial lifestyles, we have seen a decline in the diversity and quantity of microbiota, through increased antibiotics use, antibacterial hyenine measures, less contact with biodiverse ecosystems and soils, and industrial westernized diets (Schnorr et al. 2014). Higher diversity is instead found in more traditional lifestyles with direct contact with biodiverse environments and diets based on low fat/high fiber unprocessed foods (Schnorr et al. 2014; Ruggles et al. 2018).

\section{Biodiverse Diets}

Today, we ignore and therefore underestimate the extraordinary biodiversity of plants which the peasants of past centuries enjoyed and bred, along with the vast knowledge they had of species and variety. Over thousands of years, and long before modern plant breeding, farmers bred, planted, harvested, saved and exchanged seed which was constantly evolving to be able to adapt to the specific environmental characteristics and climatic conditions of each particular territory. Throughout the millennia they built a large reservoir

\section{Footnote 14 (continued)}

in the production of compounds such as alkaloids, polyphenols, flavonoids, and terpenoids which also make up medicinal or aromatic properties of plants. 
of knowledge about their crops, their characteristics and possible uses, and how they interacted with the surrounding environment (Navdanya International 2013; Food for Health Manifesto 2019; Thrupp 2000). These domesticated wild plants and animals were also actively managed to establish an array of nutritional requirements, guaranteeing the availability of food throughout the seasons, all in tandem with ecosystem conservation, assuring resilience and longevity of a healthy planet for new generations.

We see this in traditional diets, evolving from these agroecosystem management practices, ranging from Ayurvedic diets in India, the Mediterranean diet in Europe and many others. For example, the Mediterranean diet, being one of the most well-studied diets in the world, is composed of a variety of fruits, vegetables, mostly unrefined cereals, legumes, nuts, fish, meats, and olive. As another example, the use of wild edible foods in many parts of the world is also traditionally used to supplement proteins, essential minerals, micronutrients, and vitamins (Ray et al. 2020). In India over 1,400 species of wild greens, seeds, tubers constitute a wide diversity of easily accessible, time tested nutrition sources which form part of local traditional diets (Ray et al. 2020). Such examples form the basis of minimally processed, high fiber, and diversity-based diets which have protective effects against a variety of modern noncommunicable diseases (von Hertzen et al. 2011). These interconnected relationships lead to better human health, environmental health as well as active conservation and cultivation of biodiversity at all levels.

\section{The Industrial Agricultural System and the Erosion of Biodiversity}

Industrialization and globalization have profoundly changed the way we produce, distribute, prepare, and consume food, having affected every area of the food system. This modern, industrialized, and globalized food system model is based on monocultures, pesticide use, genetically modified and high yield variety seed and artificial fertilizers. Agriculture and food processing systems are degrading the environment through greenhouse gas production, depletion of the soil biome and all other surrounding life through pesticides and monocultural farming, soil erosion and water depletion, as well as energy-intensive food processing methods.

In other words, the same system that is having a devastating impact on environmental health, is also putting our health at risk (Food for Health Manifesto 2019). This goes on to constitute a two-fold health burden from industrial agriculture and food processing. The first is the health costs resulting from the toxins and contaminants in our food, as ingredients commonly found in pesticides, such as glyphosate have been ruled to be potentially carcinogenic (Gasnier et al. 2009). The second is the loss of biodiversity and diversity of nutrients in our diets that are essential to good health. In two long-range studies done in the US and the UK, it was found that mineral content in food had significantly declined from the period of 1940-2002 (Davis et al. 2004; Thomas 2007). Since 1940, magnesium in vegetables overall has gone down by $24 \%$, in carrots all nutrients have dropped by $75 \%$ (significant since carrots are a rhizosphere vegetable), spinach has lost $53 \%$ of its potassium and $60 \%$ iron, and fruits like cherries, peaches and strawberries saw a $27 \%$ loss of zinc (Thomas 2007). In the study by the University of Texas, there marked a significant decline of 43 US fruits and vegetables in protein, calcium, vitamin $\mathrm{C}$, vitamin B2 and iron, directly linked to modern agricultural practices (Davis et al. 2004) In a vicious circle, environmental degradation is reducing the quality and availability of basic nutrients. It is no surprise then that one in three people is suffering from micronutrient deficiencies (FAO 2015). In addition to this, the reduction of diets has led us to consume just over 200 species out of the over 6,000 varieties identified, and the great majority of people is now living off of no more than twelve plant species and five animal species (Navdanya International 2013; FAO and Commission on Genetic Resources for Food and Agriculture 2019). Today, only nine species account for $66 \%$ of total crop production, and three species-maize wheat and rice- provide $60 \%$ of our daily calories (Ceccarelli 2019; FAO 2019).

This trend constitutes a huge erosion of previously available crop varieties and species, as without their consistent cultivation many have been forever lost, rendering nutrition and food security precarious (Navdanya International 2013). This level of erosion is directly due to two factors. Firstly, monocultures make up $80 \%$ of the 1.5 billion hectares used in agricultural cultivation, of which only high-yield, commodity crops are grown (Altieri and Nicholls 2020). Secondly, the dominant method of seed production and seed breeding in industrial agriculture is based on: uniformity and homogeneity - all plants must be the same from each seed batch; stability—plants must be the same through generations; and distinctiveness - must be distinguishable from other varieties, based on the requirements to be registered to be commercially sold (Navdanya International 2013). This begs the question, how can there be a diet based on biodiversity if all seed, in order to be legally cultivated and sold, must be officially registered under these requirements? (Food for Health Manifesto 2019; Ceccarelli 2019) Modern-day industrial seed breeding seeks consistency of plant production in space, meaning the same plant variety must produce a uniform crop. While traditionally farmers bred for consistency through time to build resilience in a variety to ensure successful harvest throughout the generations (Navdanya International 2013). Regardless, the trend of industrial seed breeding fits well with industrial agriculture's requirement 
for a uniform response to the application of chemicals to control pests, diseases and weeds, or fertilizers. This is especially so when considering the same five corporations which produce the majority of these pesticides and fertilizers hold a $55 \%$ monopoly over the 61.5 billion dollar world seed market. ${ }^{15}$ In the end, promoting genetic homogenization which is exported globally (Navdanya International 2013).

This industrial agricultural trend is therefore driving a global dietary transition in which traditional diets high in fiber and micronutrients are replaced by diets higher in refined sugars, refined fats, oils, meats and highly processed foods (Iketch 2011; Singh et al. 2017; Ruggles et al. 2018; Food for Health Manifesto 2019; Blum et al. 2019). This results in the depletion of the human microbiome, lack of basic nutrients, as well as food being potentially contaminated with carcinogenic and endocrine disrupting chemicals from agrochemical residues, artificial growth hormones, and antibiotic resistant strains of bacteria (Iketch 2011; von Hertzen et al. 2011; Mancabelli et al. 2017). These shifts are directly related to the huge explosion of noncommunicable diseases, such as a variety of inflammatory diseases, food allergies, psychiatric disorders, diminishing fertility, cancers, obesity, cardiovascular disease, diabetes and so on (von Hertzen et al. 2011; Food for Health Manifesto 2019; Ceccarelli 2019). This becomes especially significant in the context of the COVID-19 pandemic, where such preconditions have been shown to result in greater risk of hospitalization and death. In Italy, a preliminary report in March 2020 showed that $99 \%$ of coronavirus deaths were of people with preexisting conditions, $49.5 \%$ of which had three or more illnesses. ${ }^{16}$ In general, the most common comorbid illnesses being hypertension, cardiovascular disease, and diabetes, with higher likelihood of death being found in patients with immune and metabolic disorders, cancers, and respiratory diseases (Khan et al. 2020; Garg 2020). These are the exact diseases being caused by industrial food diets.

The importance of our food system takes on an even higher precedence as that the release of new zoonotic diseases, which could cause new pandemic outbreaks, are linked to ecological degradation caused by industrial agriculture. Not to mention the possible disease concentration and creation of 'superviruses' which pass through genetically identical, and sick livestock in factory farms (Wallace 2016). This becomes more severe since animals who live near and eat industrial, nutrient deficient foods, suffer from the similar noncommunicable diseases as humans, resulting

\footnotetext{
15 https://www.marketsand markets.com/PressReleases/seed.asp Accessed October 2020.

16 https://www.bloomberg.com/news/articles/2020-03-18/99-of-those -who-died-from-virus-had-other-illness-italy-says Accessed May 2020. Original report: https://www.epicentro.iss.it/coronavirus/bolle ttino/Report-COVID-2019_17_marzo-v2.pdf.
}

in a lowering of their immune system (Iketch 2011). Considering we use the worst of industrial agricultural crops to feed industrially farmed animals, this creates a huge risk for the rise in new diseases (Wallace 2016).

\section{Industrial Agriculture's False Solutions}

Although most international actors agree that our current food system is broken, not all agree on how the call for 'food systems transformation' should go. Now, the COVID public health crisis and its resulting economic devastation has accelerated calls to respond through the 'Great Reset' of capitalism through embracing the fourth industrial revolution. ${ }^{17}$ For food systems, this would mean a 'food systems transformation' towards a more vertically integrated food supply chain through further centralization, digitization and mined data in the false names of 'public health', 'economic recovery' and climate change and biodiversity-loss mitigation. Practically, this translates to a more aggressive push toward false technical solutions such as farms managed through artificial intelligence and predictive algorithms, precision farming, fake foods-such as lab-grown meat and synthetically produced oils-, robot pollinators, biofortification, gene drives for more advanced forms of GMOs, and digital sequencing genetic information (DSI) of agro-diversity (Shiva et al. 2018). Under the excuse of the COVID-19 emergency, we are seeing a fast-tracking of these technologies with little regard for their (known and unknown) social, ecological or health effects.

In other words, these 'solutions' to the biodiversity, nutrition, hunger, climate, ecological and health crises are being touted as the new 'smart' and 'innovative' ways to improve our food systems (Shiva et al. 2018). While it has become extremely tempting to frantically, and therefore blindly, look for immediate fixes for these crises, in reality, these false solutions reside in a 'solutionist' mentality that sees technology as the single, and only, mechanism to solving complex problems. In actuality, this relies on an amnesia and heavy denial of how agricultural technology developed for the Green Revolution has created and shaped these compounding crises to begin with. Ignoring these facts risks the further accumulation of negative feedback loops of endlessly trying to solve the problem that technological and industrial solutions created in the first place, leaving these unsolved structural problems that perpetuate further crises. In turn, large corporations then finds new ways to profit off the rot

\footnotetext{
17 https://www.weforum.org/agenda/2016/01/the-fourth-industrial -revolution-what-it-means-and-how-to-respond/ https://www.weforum.org/agenda/2020/06/now-is-the-time-for-agreat-reset/ Accessed May 2020.
} 
they left behind, selling us these 'new' solutions as necessary to fix the problems they have caused.

Regardless of these facts and of the international recognition for the need to safeguard biodiversity at all levels, these types of technological 'quick-fixes' are now being supported by international organizations and world leaders who stand hand-in-hand with big corporations' desires for furtheragrifood system concentration. While corporate actors might agree that something must be done about our health and environmental crises, international alliances with philanthro-capitalists like Bill Gates and other large corporations mask where their real interest lies: in accelerating the research-to-product-to-profit pipeline for these marketable technologies. For example, the new FAO Director General Qu Dongyu, stressing the importance of partnership with the private sector, has invited agri-tech company CropLife ${ }^{18}$ to join in a letter of intent to move toward a digital food systems transformation. ${ }^{19}$ Such partnerships and strategies risk allowing agribusiness corporations to gain further control over every aspect of the food supply production, distribution and consumption chain, as so often sought out by their monopolistic intents.

Hence, these types of partnerships are resulting in a steady degradation of our international governance landscape, meant to safeguard food systems, biodiversity, and therefore health. Another such example is the erosion of legitimacy of international biodiversity agreements such as the Convention of Biological Diversity and the Nagoya protocol, which is intended to set up governance mechanisms to safeguard access to the world genetic resources. Private interests now threaten to push a more mercantile view of biodiversity as potentially patentable genetic information. This means patented genetic information is then used to develop new types of GMO seeds, and one of their uses is biofortification. Biofortification is the enhancement of a particular crop variety with a certain nutrient, either through breeding or, most commonly, through genetic modification. This is done through isolating the role of an individual nutrient from the vast biodiverse web described above, synthesizing it, and creating a new seed variety to be commercialized and sold. This supplementation is touted as a premier way to combat malnutrition, but in reality, nutrients rarely work in isolation as it has been acknowledged that no single component or nutrient of a healthy diet has a demonstrable

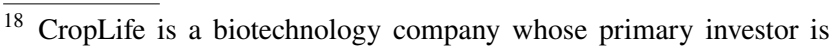
the Bill and Melinda Gates Foundation, and frequently co-invests with companies like Monsanto or Bayer, Dupont/ Pioneer Hi-bred, KWS SAAT AG, and Syngenta. For more see: https://navdanyain ternational.org/wp-content/uploads/2020/10/GATES-TO-A-GLOBA L-EMPIRE-FULL-REPORT-13.10.2020-3.pdf.

19 https://www.fao.org/news/story/en/item/1311286/icode/ Accessed October 2020
}

protective effect by itself (Food for Health Manifesto 2019). Besides the various problems with biofortification initiatives, the mere supplementation of one nutrient does not solve the problem of overall malnutrition, or even why there are decreased nutrition levels in crops to begin with. Hence, this means acting as a surface level solution to the actual problem of global malnutrition, ignoring the important role of biodiversity in health.

\section{The Biodiversity-based Agroecological Paradigm}

It now becomes clear how the current industrial agrifood model engages in a mutually destructive relationship with environmental health and human health, providing little viable pathways for true food systems transformation. Instead, what is needed is a more socially just, ecologically protective, and nutritionally resilient transformation. In this sense, agroecological, organic farming shows us a systemic approach to addressing issues of biodiversity loss, nutritional and food security, and resiliency to respond to a variety of crises. Agroecology places biodiversity at the heart of its approach to mimicking natural ecosystem functioning. This means a completely different approach: alternative animal production models that contribute to an integrated ecosystem, restoration of landscapes to increase natural fertility and conserve nutrients, and the ecological management of pests and diseases (Altieri and Nicholls 2020). Such an approach then leads to improved soil fertility, sustained and diversified yields for better nutritional and livelihood security, toxic-free food, biodiversity conservation, containment of pathogens and hence, better plant, animal and human health (Altieri and Nicholls 2020).

For example, when toxic chemicals and monocultures are no longer used, surrounding life has the space to flourish and thrive as they are no longer being harmed (Altieri and Nicholls 2004). This works to integrate surrounding wild landscapes into the agroecological system, allowing better access and conservation of wild biodiversity, wild foods, medicines and other resources. Maintenance of these wild spaces also provides and maintains a barrier against the releasing of zoonotic diseases due to ecosystem displacement. ${ }^{20}$ A crucial necessity as ecological displacement has been responsible for the release of $70 \%$ of new diseases since

\footnotetext{
${ }^{20}$ https://mronline.org/2020/03/17/how-global-agriculture-grew-apandemic/ Accessed 5 October 2020.
} 
the 1940s, not least of which, possibly being Coronavirus ${ }^{21}$ (FAO 2017).

This type of biodiversity-based,agroecological, organic food systems transformation, in opposition to corporate controlled ecologically destructive globalized food systems, has been advocated for by movements throughout the world in the name of food sovereignty. Embodying a different vision of what food systems, from seed to table, could be, these movements are already transitioning toward an ecological and democratic food systems transformation through preserving seeds, soils, biodiversity and nutrition. They are formed by a variety of actors, including small farmers, gardeners, civil society organizations, citizens, policy makers, researchers, and international organizations. And they embrace a diversity of methods and approaches, including agroecological farming, local/ zero kilometer food chains, cooperative models of production and consumption, community supported agriculture (CSAs), farmers markets, biodistricts, ${ }^{22}$ community and school gardens, urban farms, ${ }^{23}$ community seed banks ${ }^{24}$ and slow food movements. Such movements and approaches are rooted in and adapt to local contexts to fit local needs, traditions, and knowledge systems. This also includes reviving traditional food heritage, such as the case with wild or forgotten foods. ${ }^{25}$ Through these diverse methods, small farmers are feeding their local communities with healthy, nutritious food while simultaneously preserving ecosystemic health. ${ }^{26}$

These types of local food systems are also more resilient to sudden crisis, as has been shown during the COVID-19 pandemic, with the surge of Community Supported Agriculture (CSA) programmes, solidarity economies, consumer cooperatives, local credits and community agricultural productions (Altieri and Nicholls 2020). ${ }^{27}$ Demonstrating flexibility in comparison to large scale industrial farms whose

\footnotetext{
$21 \mathrm{https}: / /$ mronline.org/2020/03/17/how-global-agriculture-grew-apandemic/ Accessed 5 October 2020. https://www.ipes-food.org/_ img/upload/files/COVID-19_CommuniqueEN.pdf.

https://www.grain.org/en/article/6437-new-research-suggests-indus trial-livestock-not-wet-markets-might-be-origin-of-covid-19\#sdfoo tnote6sym Accessed May 2020.

${ }^{22}$ In Italy: https://biodistrettoamerina.com/.

${ }^{23}$ In the USA: https://austin.culturemap.com/news/restaurant s-bars/03-30-20-austin-farms-urban-farm-stands-fresh-produce-veget ables-boggy-creek-hausbar-johnsons-backyard-garden/.

${ }^{24}$ In India: https://www.navdanya.org/site/living-seed/navdanyaseed-banks.

25 https://indiatogether.org/articles/tribal-food-fest-underlines-fooddiversity-agriculture Accessed September 2020.

26 https://www.csm4cfs.org/wp-content/uploads/2017/12/CSMCo mments_FirstDraft_CFSPolicyRecs_Final.pdf Accessed October 2020 .

27 https://www.npr.org/2020/05/10/852512047/as-food-supply-chain -breaks-down-farm-to-door-csas-take-off Accessed May 2020.
}

rigid supply chains collapsed, with prices wildly fluctuating, after just two months of lockdown. ${ }^{28}$

It is also important to note that agroecological methods cannot co-exist with existing conventional industrial agriculture and Green Revolution methods, regardless of corporate narratives that try to assimilate agroecology as a means to their already existing business models. ${ }^{29}$ Agroecology and its resulting local iterations in fact require a complete paradigm shift away from hyper-centralized, predatory corporate-controlled industrial globalization, which has created and lies at the root of our compounding crises. Meaning an agroecological food systems transformation would also see a profound shift of food governance structures to democratic community-controlled systems, where communities have rights over their seeds, lands, and there are safeguards against conflict of interests. This would include prioritizing human and nature rights over trade and investment interests to ensure respect for the environment and natural resources, for cultural and biological diversity, and human values.

Therefore, what is required is a paradigm shift which recognizes that biodiversity has more than just nutritional and economic significance. For instance, the exchange of farmers' seeds is not just the exchange of pieces of genetic information or mere nutrients. The free exchange of seeds embodies a worldview which holds reverence for the continuity of life and its heritage (Navdanya 2012). Farmers gather knowledge on plants, seeds and their interrelationships in local ecosystems through watching them grow in other farmers' fields. Exchanging knowledge around cultural, religious, gastronomic, drought/disease/pest resistance, and other community values. A base of knowledge which is derived from direct interactions with the land and subsequently with community members which recognizes that all forms of Nature interact and influence the others to form a web of life (Navdanya 2012). The farmer herself is a steward or a custodian of this diversity to be passed on. The free exchange of this knowledge, encapsulated in a seed, ensures the survival of and the long-term resiliency of that variety, species, and knowledge, and hence that culture and community. In recognition of these deep interconnection, diversity of both plants and animals holds meaningful significance in the cultural ecosystems of local places.

For example, in India, many plants, flowers, seeds, and foods are considered sacred or are given religious and cultural significance. Plants such as paddy, coconut, millets, ginger, gooseberry, cardamom, and chickpea hold religious significance in many parts of India, either as components of religious festivals or as auspicious offerings (Navdanya

\footnotetext{
${ }^{28} \mathrm{https}: / / \mathrm{w} w \mathrm{w} . z e r o h e d g e . c o m / m a r k e t s /$ price-half-worlds-stapl e-food-70-2020 Accessed April 2020

${ }^{29}$ https://www.csm4cfs.org/wp-content/uploads/2017/12/CSMCo mments_FirstDraft_CFSPolicyRecs_Final.pdf Accessed October 2020 .
} 
2012). Indian seed festivals reinforce a sense of gratitude and a sense of intimacy with the Earth as mother, who feeds the millions of life forms of the world (Navdanya 2012). This intimacy leads to the conservation and stewardship of local ecosystems, as farmers and communities become engaged in direct relationship with it. Allowing for a way of life that leads humans to co-create and co-produce with nature, acknowledging and working with natural cycles and the sanctity of all beings to maintain the web of life.

\section{The Two Pathways Forward}

The pandemic, compounded with an already ongoing climate, ecological and biodiversity crisis, coupled with ballooning social inequalities, has placed us at a juncture. On the one hand we can follow the current international trend to continue the concentration of industrial agriculture and convergence of digital and financial technologies to vertically integrate the entire food chain - from seed to table-rendering our food systems more vulnerable overall (Shiva et al. 2018). Continuing down this path would risk the continual destruction of human and ecological health, a phenomenon whose consequences are now coming to fruition.

On the other hand, we also have the opportunity to truly foster an ecological approach to food and agriculture, taking into deep account the web of biodiversity discussed, to help foster and protect Earth and human health. This transformation is possible through agroecological and organic approaches, who use biodiversity to provide resilience. Therefore, we must recognize and move toward a worldview that recognizes humanity as intimately interconnected and enmeshed in the web of all life as intrinsically a part of nature. What we do to the planet affects us directly. A fact which requires a full and complete recognition, and rebalancing of power toward a biodiversity-based agroecological paradigm, which recognizes and respects the diversity of locally derived indigenous, traditional and peasant knowledge and puts food sovereignty at its center. This goes then beyond just mere nutrition, and into a different worldview of deep intimacy with the land. A worldview that holds respect for the diversity of all life.

\section{References}

Altieri, Miguel A., and Clara I. Nicholls. 2020. Agroecology and the reconstruction of a post-COVID-19 agriculture. The Journal of Peasant Studies 47 (5): 881-898. https://doi.org/10.1080/03066 150.2020.1782891.

Altieri, Miguel, and Clara Nicholls. 2004. Biodiversity and pest management in agroecosystems, 2nd ed. New York: CRC Press.
Blum, Winfried E.H.., Sophie Zechmeister-Boltenstern, and Katharina M. Keiblinger. 2019. Does soil contribute to the human gut microbiome? Microorganisms 7 (9): 287. https://doi.org/10.3390/ microorganisms 7090287.

Ceccarelli, Salvatore. 2019. Nurturing diversity in our guts and on our farms to reduce health risks and increase food system resilience. The Future of Food, 45-51. Rome, Italy: Navdanya International. https://navdanyainternational.org/publications/the-future-of-foodfarming-with-nature-cultivating-the-future/.

Davis, Donald R., David R., Melvin D. Epp, and Hugh D. Riordan. 2004. Changes in USDA food composition data for 43 garden crops, 1950-1999. Journal of the American College of Nutrition 23(6): 669-682. https://saveoursoils.com/userfiles/downl oads/1351255687-Changes\%20in\%20USDA $\% 20$ food $\% 20$ com position $\% 20$ data $\% 20$ for $\% 2043 \% 20$ garden $\% 20$ crops, $\% 20195$ 0-1999.pdf.

FAO. 2015. Agroecology for food security and nutrition: proceedings of the FAO international symposium. Rome: FAO. https://www. fao.org/3/a-i4729e.pdf.

FAO. 2017. The future of food and agriculture: trends and challenges. Rome: Food and Agriculture Organization of the United Nations.

FAO, and Commission on Genetic Resources for Food and Agriculture. 2019. In The State of the World's Biodiversity for Food and Agriculture, ed. J. Bélanger and D. Pilling. Rome: Food and Agriculture Organization of the United Nations. http://www.fao.org/3/ CA3129EN/CA3129EN.pdf.

Garg, Shikha. 2020. Hospitalization rates and characteristics of patients hospitalized with laboratory-confirmed coronavirus disease 2019-COVID-NET, 14 States, March 1-30, 2020. Morbidity and Mortality Weekly Report 69 (15): 458-464. https://doi. org/10.15585/mmwr.mm6915e3.

Gasnier, Céline., Coralie Dumont, Nora Benachour, Emilie Clair, Marie-Christine. Chagnon, and Gilles-Eric. Séralini. 2009. Glyphosate-based herbicides are toxic and endocrine disruptors in human cell lines. Toxicology 262 (3): 184-191. https://doi. org/10.1016/j.tox.2009.06.006.

Hirt, Heribert. 2020. Healthy soils for healthy plants for healthy humans. EMBO Reports 21 (8): 1-5. https://doi.org/10.15252/ embr.202051069.

Iketch, John. 2011. Healthy soils, healthy people; the legacy of William Albrecht. Columbia: University of Missouri. https://sites .google.com/site/albrechtlecture/home/text-of-2011-albrecht-lectu re\#_ftn2.

Khan, Mostaured, Nuruzzaman Khan, Golam Mustagir, Juwel Rana, Saiful Islam, Iqbal Kabir. 2020. Effects of underlying morbidities on the occurrence of deaths in COVID-19 patients: a systematic review and meta-analysis. MedRxiv, May, 2020.05.08.20095968. https://doi.org/10.1101/2020.05.08.20095968.

Mancabelli, Leonardo, Christian Milani, Gabriele Andrea Lugli, Francesca Turroni, Chiara Ferrario, Douwe van Sinderen, and Marco Ventura. 2017. Meta-analysis of the human gut microbiome from urbanized and pre-agricultural populations. Environmental Microbiology 19 (4): 1379-1390. https://doi.org/10.1111/14622920.13692.

Food for Health Manifesto. 2019. Cultivating biodiversity, cultivating health. New Delhi, Rome: International Commission on the Future of Food and Agriculture; Navdanya International. https:// navdanyainternational.org/publications/manifesto-food-for-healt $\mathrm{h} /$.

Navdanya International. 2013. The law of the seed Florence. Italy: International Commission on the Future of Food and Agriculture. https://navdanyainternational.org/wp-content/uploads/2013/05/ lawofseed.pdf.

Navdanya. 2012. Seed: The embodiment of cultural diversity. In Seed freedom: a global citizen's report, 8-9. New Delhi: Navdanya. 
https://navdanya.org/attachments/Seed\%20Freedom_Revised_810-2012.pdf.

Ray, Avik, Rajasri Ray, and E.A. Sreevidya. 2020. How many wild edible plants do we eat-their diversity, use, and implications for sustainable food system: an exploratory analysis in India. Frontiers in Sustainable Food Systems 4 (56): 1-21. https://doi. org/10.3389/fsufs.2020.00056.

Ruggles, Kelly V., Jincheng Wang, Angelina Volkova, Monica Contreras, Oscar Noya-Alarcon, Orlana Lander, Hortensia Caballero, and Maria G. Dominguez-Bello. 2018. Changes in the gut microbiota of urban subjects during an immersion in the traditional diet and lifestyle of a rainforest village. MSphere, e00193-18, 3 (4): 1-8. https://doi.org/10.1128/mSphere.00193-18.

Salonen, Anne, Jarkko Salojärvi, Leo Lahti, and Willem M. de Vos. 2012. The Adult Intestinal Core Microbiota Is Determined by Analysis Depth and Health Status. Clinical Microbiology and Infection: The Official Publication of the European Society of Clinical Microbiology and Infectious Diseases 18 (Suppl 4): 16-20. https://doi.org/10.1111/j.1469-0691.2012.03855.x.

Schnorr, Stephanie L., Marco Candela, Simone Rampelli, Manuela Centanni, Clarissa Consolandi, Giulia Basaglia, Silvia Turroni, et al. 2014. Gut microbiome of the hadza hunter-gatherers. Nature Communications 5 (1): 3654. https://doi.org/10.1038/ncomm s4654.

Shiva, Vandana, Kartikey Shiva, and Neha Raj Singh. 2018. The future of our daily bread: regeneration or collapse? New Delhi: Navdanya International; RFSTE. https://navdanyainternationa 1.org/publications/the-future-of-our-daily-bread-regeneration-orcollapse/.

Singh, Rasnik K., Hsin-Wen. Chang, Di. Yan, Kristina M. Lee, Derya Uçmak, Kirsten Wong, Michael Abrouk, et al. 2017. Influence of diet on the gut microbiome and implications for human health. Journal of Translational Medicine 15 (1): 73. https://doi. org/10.1186/s12967-017-1175-y.
Thomas, David. 2007. The mineral depletion of foods 1940-2002-a review of the 6th edition of McCance and Widdowson. Nutrition and Health 19: 21-55. https://mineralresourcesint.co.uk/pdf/ Mineral_Depletion_of_Foods_1940_2002.pdf.

Thrupp, Lori Ann. 2000. Linking agricultural biodiversity and food security: the valuable role of agrobiodiversity for sustainable agriculture. International Affairs 76 (2): 265-281. https://doi. org/10.1111/1468-2346.00133.

von Hertzen, Leena, Ilkka Hanski, and Tari Haahtela. 2011. Natural immunity: biodiversity loss and inflammatory diseases are two global megatrends that might be related. EMBO Reports 12 (11): 1089-1093. https://doi.org/10.1038/embor.2011.195.

Wagg, Cameron, S. Franz Bender, Franco Widmer, and Marcel G. A. van der Heijden. 2014. Soil biodiversity and soil community composition determine ecosystem multifunctionality. Proceedings of the National Academy of Sciences 111 (14): 5266-5270. https:// doi.org/10.1073/pnas.1320054111.

Wallace, Rob. 2016. Big farms make big flu: dispatches on influenza, agribusiness, and the nature of science. Illustrated. New York: Monthly Review Press.

Wardle, David A., Richard D. Bardgett, John N. Klironomos, Heikki Setälä, Wim H. van der Putten, and Diana H. Wall. 2004. Ecological linkages between aboveground and belowground biota. Science 304 (5677): 1629-1633. https://doi.org/10.1126/scien ce. 1094875 .

Publisher's Note Springer Nature remains neutral with regard to jurisdictional claims in published maps and institutional affiliations. 